\title{
PREPARATION AND CHARACTERIZATION OF NANOCRYSTALS FOR SOLUBILITY AND DISSOLUTION RATE ENHANCEMENT OF PALIPERIDONE USING DIFFERENT HYDROPHILIC CARRIERS: IN VITRO-IN VIVO STUDY
}

\author{
MOON RAJKUMAR*, GATTANI SURENDRA \\ Department of Pharmaceutics, School of Pharmacy, Swami Ramanand Teerth Marathwada University, Nanded - 431 606, Maharashtra, \\ India. Email: rajmun@rediffmail.com
}

Received: 26 January 2018, Revised and Accepted: 09 March 2018

ABSTRACT

Objective: The objective of this study was to increase the solubility and dissolution rate of paliperidone (PAL) by preparing its nanocrystals using different hydrophilic carriers by antisolvent precipitation technique.

Methods: The nanoparticles (NP) were characterized for aqueous solubility, drug content, Fourier transform infrared spectroscopy, differential scanning calorimetry, X-ray diffraction, scanning electron microscopy, particle size, and in vitro-in vivo analysis.

Results: The results showed improved solubility and dissolution rate of NPs when compared to pure drug and physical mixture (PM). Solubility data showed a linear graph giving an indication that there is a gradual increase in the solubility profile of the drug with an increase in concentration of the carriers. At highest concentration, the solubility of NPs with Plasdone S630, Povidone K-25, and PVP K-30 found to be increased by 12 folds, 9 folds and 6 folds, respectively, as compared to pure drug. The release profile of NPs with Plasdone S630 in terms of dissolution efficiency at 60 min (DE60), initial dissolution rate (IDR), amount release in $15 \mathrm{~min}$ (Q15 min), and time for 75\% release (t75\%) shows better results when compared to pure drug, PM, and also NPs with povidone 25 and povidone 30. In vivo study reveals that optimized NPs elicited significant induction of cataleptic behavior which is the indication of antipsychotic agent(s) effect.

Conclusion: The process antisolvent precipitation under constant stirring may be a promising method to produce stable PAL NPs with markedly enhanced solubility and dissolution rate due to nanonization with the increased surface area, improved wettability, and reduced diffusion pathway.

Keywords: Paliperidone, Nanocrystals, Dissolution, Plasdone S630, Povidone K25, Povidone K30.

(C) 2018 The Authors. Published by Innovare Academic Sciences Pvt Ltd. This is an open access article under the CC BY license (http://creativecommons. org/licenses/by/4. 0/) DOI: http://dx.doi.org/10.22159/ajpcr.2018.v11i4.24964

\section{INTRODUCTION}

Pharmaceutical scientists in industry, especially, involved in drug discovery and formulation development face major problems of poor aqueous solubility and slow dissolution rates of drugs [1,2]. Insoluble drugs are not adequately wetted and dissolved in GIT after oral administration, consequently affecting their in vivo performance [2]. Therefore, there is a need to find a universal remedy which will increase the solubility of poorly soluble drugs; this can be achieved by nanoparticle (NP) engineering process [3-5] by reducing the particle size to nano range $[6,7]$. Paliperidone (PAL) is a weakly acidic, poorly soluble antipsychotic drug. The present study aims to prepare PAL nanocrystals using different hydrophilic carriers by antisolvent precipitation technique to facilitate the enhancement of solubility, dissolution, and bioavailability in turn $[8,9]$.

\section{MATERIALS AND METHODS}

Materials

PAL was obtained from Cadila Pharmaceuticals, Ahmedabad, India. Plasdone S-630, Povidone K25, and Povidone K30 were generously gifted by Ashland, Wayne, New Jersey, USA. All other chemicals used were of analytical grade.

\section{Preparation of PAL NPs}

PAL nanocrystals with hydrophilic carriers (Plasdone S630/Povidone K25/Povidone K30) of different weight ratios were prepared by dissolving an appropriate amount of carrier in $200 \mathrm{ml}$ of mili-Q water and the solution stirred at $1000 \mathrm{rpm}$ on a magnetic stirrer. A specified amount of PAL was dissolved in $10 \mathrm{ml}$ chloroform to prepare an organic solution, and this solution was then injected into $200 \mathrm{ml}$ aqueous solution containing hydrophilic carrier maintained at $37 \pm 2{ }^{\circ} \mathrm{C}$ under constant stirring at $1000 \mathrm{rpm}$ (REMI 1 ML Magnetic Stirrer) [10]. The obtained NPs were subsequently stored in a vacuum oven at room temperature for $48 \mathrm{~h}$ to remove the residual solvent. The dried NPs were pulverized and sieved through sieve number \#170. The samples were kept in desiccators and further stored in airtight vials (Table 1) [11-20].

\section{Preparation of physical mixture (PM)}

PMs of different hydrophilic carriers with drug were prepared by triturating in a mortar and pestle for $30 \mathrm{~min}$.

\section{Determination of saturation solubility}

Saturation solubility of PAL, PM, and NPs was determined by adding the known excess amount to $100 \mathrm{ml}$ HPLC grade water (pH 7.00 at $20^{\circ} \mathrm{C}$ ) which was then shaken at $100 \mathrm{rpm}$ on magnetic stirrer for $24 \mathrm{~h}$. After centrifugation and filtration through $0.45 \mu \mathrm{m}$ Nylon syringe filter, the concentration of PAL was determined spectrophotometrically at $275 \mathrm{~nm}$. Every sample was analyzed in triplicate, and the mean values and standard deviations were reported [21,22].

\section{Ratio optimization}

Based on the highest solubility and drug content, the optimized batch was selected and filled in capsules and used for further characterization.

Fourier-transform infrared spectroscopy (FT-IR)

FT-IR spectra of PAL alone and PALNPs were carried out to check compatibility of the drug with polymers. PALNP was mixed with $\mathrm{KBr}$ 
(IR grade) in the ratio of 1:100. The dispersion was then scanned using FT-IR Spectrophotometer (Shimadzu, Japan). The spectra of NPs were compared with that of the spectra of pure drug.

\section{Differential scanning calorimetry (DSC)}

A DSC-60 (Shimadzu, Japan) was calibrated using an indium standard. The samples were placed in hermetically sealed aluminum pans and heated from $30^{\circ} \mathrm{C}$ to $200^{\circ} \mathrm{C}$ at $10^{\circ} \mathrm{C} / \mathrm{min}$ and with a nitrogen purge of $40 \mathrm{ml} / \mathrm{min}$.

\section{X-ray diffraction (XRD)}

Powder XRD pattern was traced employing X-ray diffractometer (Model No.3000, Seifert, Germany) for the samples, using Ni-filtered Cu-Kradiation, a voltage of $40 \mathrm{kV}$, a current of $30 \mathrm{~mA}$ radiation scattered in the crystalline regions of the sample, which was measured with a vertical goniometer. Pattern was obtained using a step width of $0.04^{\circ}$ with a detector resolution in $2 \theta$ (diffraction angle) between $10^{\circ}$ and $50^{\circ}$ at ambient temperature.

\section{Scanning electron microscopy (SEM)}

The morphologies of PAL and nano-sized PAL were examined using a scanning electron microscope (JEOL JSM-7001F, Japan) operated at an accelerating voltage of $15 \mathrm{kV}$ and a secondary detector. Freshly prepared dispersion of sample was deposited on glass slides following the evaporation of the solvent and coated with gold.

\section{Particle size measurement}

Particle size analysis of the PAL NPs was performed by Dynamic Light Scattering (Scirocco 2000 (A), Malvern Instrument's, UK). The relative frequency of the diameter of the particle was obtained by calculation based on volume distribution. The particle size at $90 \%$ of the total fraction was used as particle size.

\section{In vitro drug release studies}

In vitro drug release study was performed using USP Apparatus I (Lab India Ltd., India) at $100 \mathrm{rpm}$ with $900 \mathrm{~mL}$ of degassed water at $37 \pm 0.5^{\circ} \mathrm{C}$. Six capsules of each batch containing nanocrystals equivalent to $6 \mathrm{mg}$ PAL were tested. Sink condition was maintained in degassed water. Sample of the dissolution media was removed through an automated sampling system at predetermined time interval $(0,5,10,15,30,45$, and $60 \mathrm{~min}$ ) and simultaneously analyzed spectrophotometrically at $\lambda \max$ of $275 \mathrm{~nm}$ (ultraviolet-1700 Shimadzu, Japan). In vitro release studies of PAL, PMs, and PALNPs were carried out, and the data of dissolution study are shown as mean \pm standard deviation $(n=6)$ [23].

\section{In vivo antipsychotic activity evaluation of PAL and PALNP4 on bar} test

The protocol was approved and implemented as per the guidelines of the Institutional Animal Ethical Committee. The severity of catalepsy in individual mouse $(\mathrm{n}=6)$ was determined as per the procedure described by Khisti et al., 2002 [24]. Briefly, placing the forepaws of the mice over a wooden bar $0.4 \mathrm{~cm}$ in diameter fixed to a height of $3.5 \mathrm{~cm}$ above the tabletop and described as descent latency. The time at which mice brought both forepaws down to the tabletop was recorded, with a maximum cutoff time of $300 \mathrm{~s}$. Measurement of catalepsy was carried out at $0 \mathrm{~min}, 30 \mathrm{~min}$, and $60 \mathrm{~min}$ after the administration of vehicle or PAL or PALNP4.

\section{RESULTS AND DISCUSSION}

\section{Solubility study of PAL and PALNPs}

The solubility of pure PAL in distilled water was found to be $1.56 \mu \mathrm{g} / \mathrm{ml}$ indicating poor solubility. The solubility studies showed a linear increase in drug solubility with increased carrier levels. At $0.7 \%$ concentration of Plasdone S630, Povidone K25, and Povidone K30, the increase in solubility was 12,9 , and 6 folds, respectively, compared with pure drug (Table 2 and Fig. 1). The increase in solubility in the presence of carrier can probably be explained by increased wettability of PAL. Hydrophilic carriers are known to interact with drug molecules mainly by electrostatic forces and occasionally by other type of forces such as hydrogen bonds [25-28].

\section{Assay of PAL}

The drug content of the prepared NPs was found to be in the range $95-101 \%$ indicating the application of the present method for the preparation of NPs with high content uniformity.

Dissolution studies of PAL, PALNPs, and PMs with different carriers The dissolution profiles showed a significant enhancement in drug release characteristics of NP and PM compared to pure PAL. The DE60 min, IDR in $15 \mathrm{~min}$, amount of release in $15 \mathrm{~min}$ (Q15 min), and time taken to release $75 \%$ ( $\mathrm{t} 75 \% \mathrm{~min}$ ) have shown higher release from NP than PM and pure drug, respectively (Table 3). Higher dissolution of NPs compared to PMs of the carrier may be due to wettability of the carrier and transformation of crystalline state of the drug to nanocrystalline in NP. Based on dissolution parameters, NP4 considered as best formulation among the other and used for further evaluation studies.

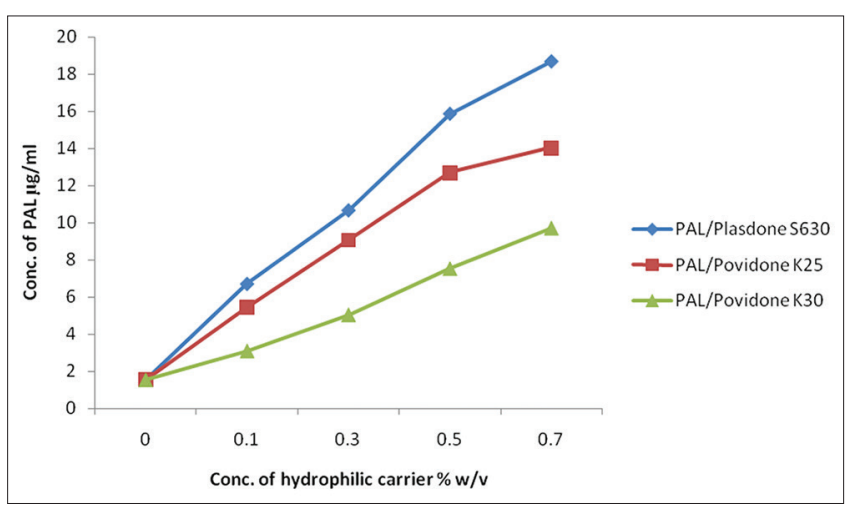

Fig. 1: Comparative solubility

Table 1: Composition of PALNPs with hydrophilic carriers

\begin{tabular}{lll}
\hline Formula & Drug/carrier & Ratio (w/w) \\
\hline NP1 & PAL/Plasdone S630 & $1: 1$ \\
NP2 & PAL/Plasdone S630 & $1: 3$ \\
NP3 & PAL/Plasdone S630 & $1: 5$ \\
NP4 & PAL/Plasdone S630 & $1: 7$ \\
NP5 & PAL/Povidone K25 & $1: 1$ \\
NP6 & PAL/Povidone K25 & $1: 3$ \\
NP7 & PAL/Povidone K25 & $1: 5$ \\
NP8 & PAL/Povidone K25 & $1: 7$ \\
NP9 & PAL/Povidone K30 & $1: 1$ \\
NP10 & PAL/Povidone K30 & $1: 3$ \\
NP11 & PAL/Povidone K30 & $1: 5$ \\
NP12 & PAL/Povidone K30 & $1: 7$ \\
\hline
\end{tabular}

PAL: Paliperidon, NP: Nanoparticle

Table 2: Solubility of PAL and PALNPs with hydrophilic carriers

\begin{tabular}{ll}
\hline Concentration of carrier & Concentration of PAL $(\boldsymbol{\mu g} / \mathbf{m l})$ \\
\hline Distilled water & $1.56 \pm 0.45$ \\
Plasdone S630\% w/v & \\
0.1 & $6.71 \pm 0.05$ \\
0.3 & $10.66 \pm 0.87$ \\
0.5 & $15.85 \pm 1.73$ \\
0.7 & $18.66 \pm 0.76$ \\
Povidone K25\% w/v & \\
0.1 & $5.47 \pm 1.03$ \\
0.3 & $9.09 \pm 0.26$ \\
0.5 & $12.71 \pm 1.45$ \\
0.7 & $14.04 \pm 0.85$ \\
Povidone K25\% w/v & \\
0.1 & $3.12 \pm 0.46$ \\
0.3 & $5.06 \pm 0.63$ \\
0.5 & $7.54 \pm 0.21$ \\
0.7 & $9.72 \pm 0.16$ \\
\hline
\end{tabular}


FT-IR

From the IR spectra of Paliperidone and Paliperidone nanoparticles 4 Figs. 2 and 3, there is no possible incompatibility between PAL and polymers within the formulation and presence of functional groups within the range. Hence, this may not affect the stability of formulation.
DSC

The DSC thermograms of PAL and NP4, as shown in Figs. 4 and 5, exhibited a sharp endothermic peak around $185.2^{\circ} \mathrm{C}$ and $181.3^{\circ} \mathrm{C}$ corresponding to melting point of drug suggesting crystalline structure. The thermogram of NP4 exhibited a broad endothermal peak around

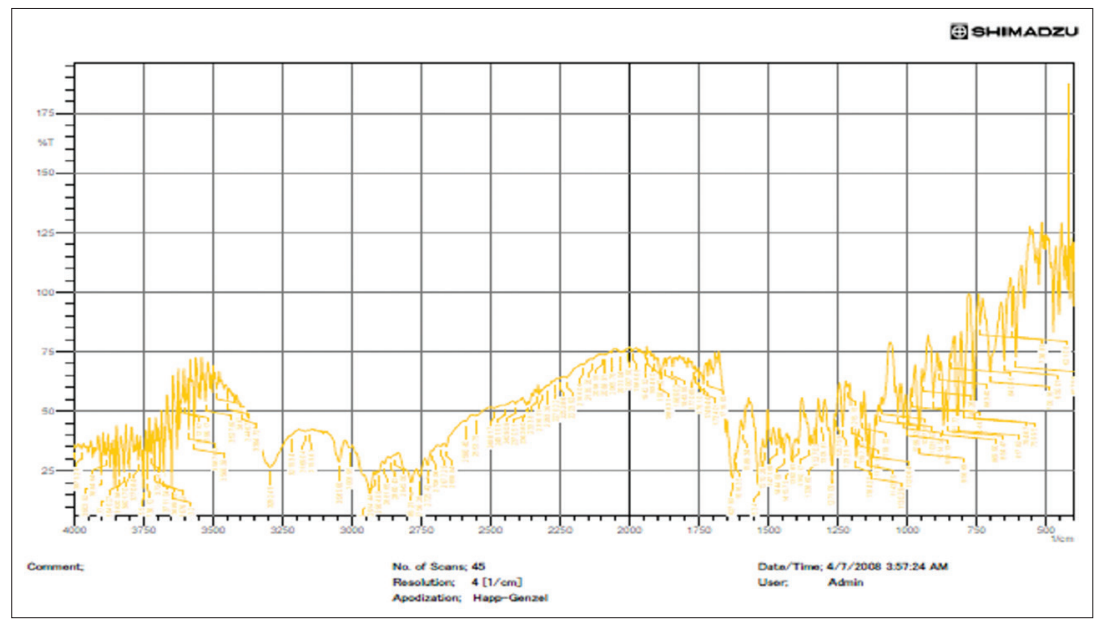

Fig. 2: Fourier-transform infrared spectroscopy spectra of paliperidone

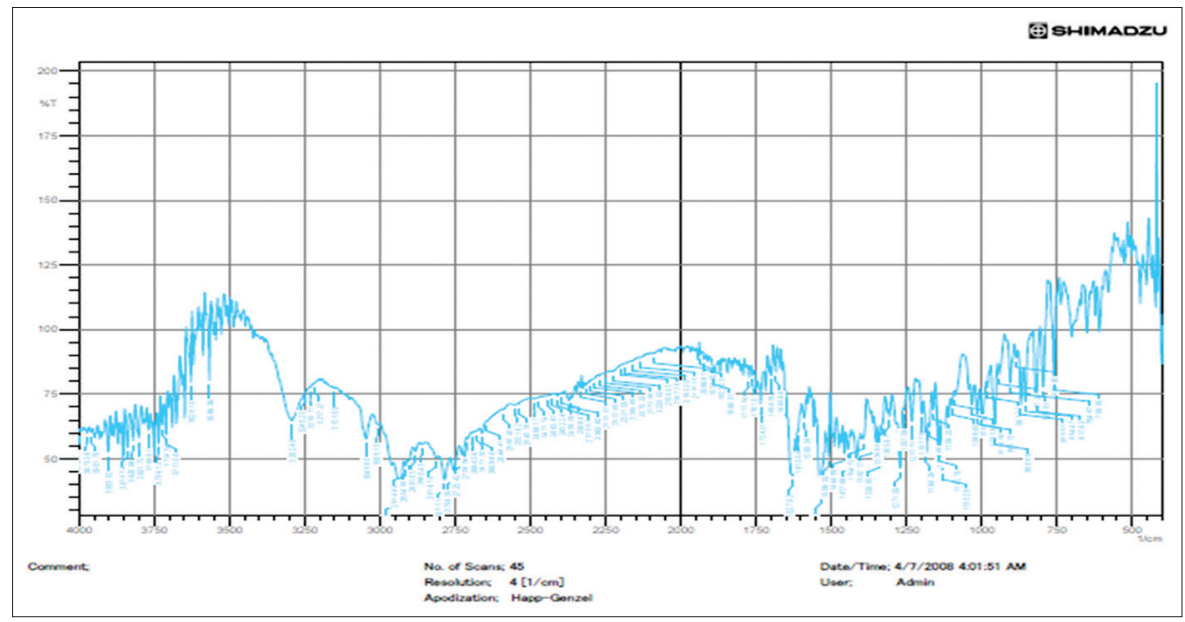

Fig. 3: Fourier-transform infrared spectroscopy spectra of paliperidone nanoparticle 4

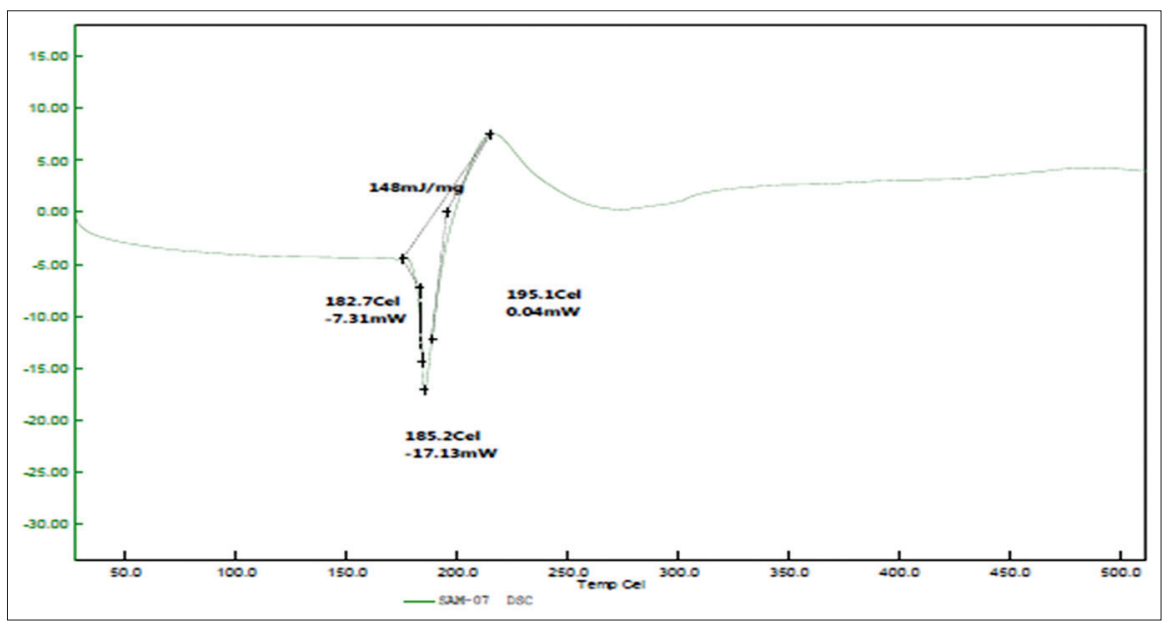

Fig. 4: Differential scanning calorimetry thermogram of paliperidone 


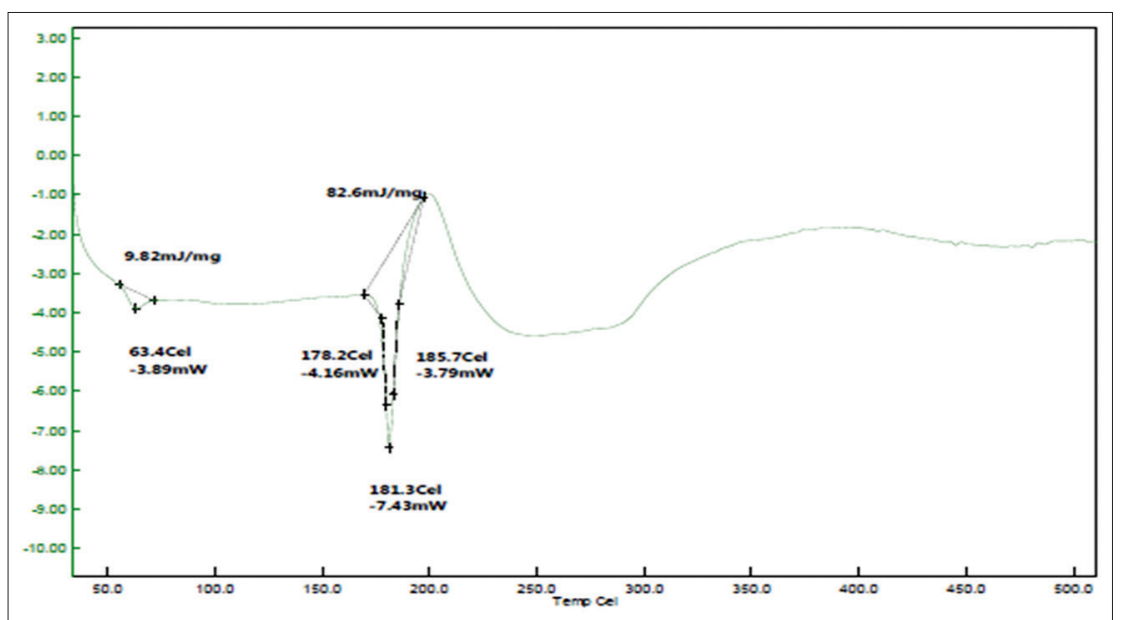

Fig. 5: Differential scanning calorimetry thermogram of paliperidone nanoparticle 4

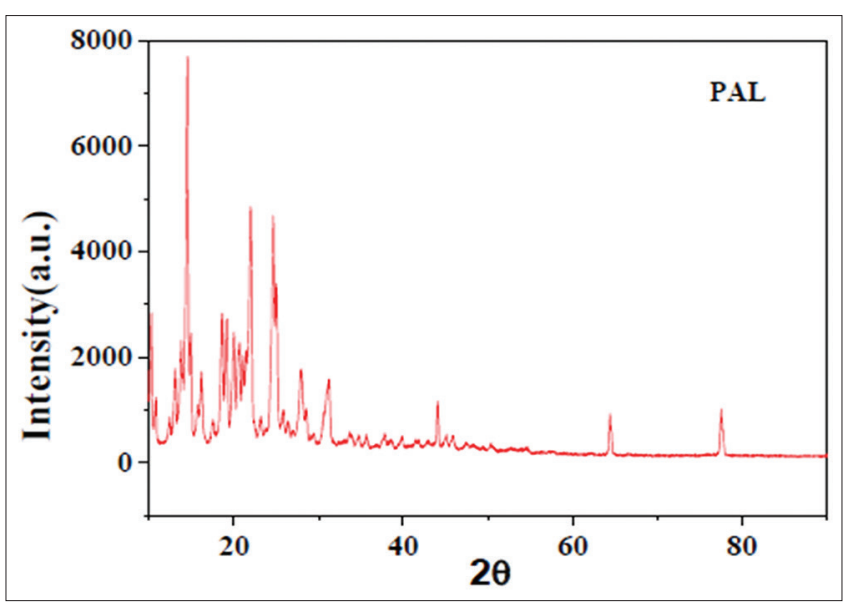

Fig. 6: Powder X-ray diffraction pattern of paliperidone

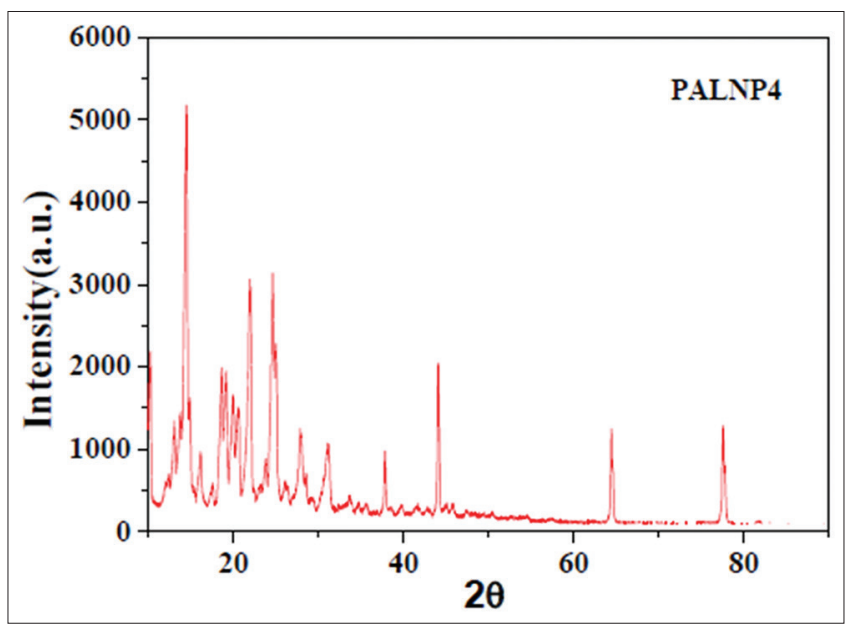

Fig. 7: Powder X-ray diffraction pattern of paliperidone nanoparticle 4

$63.4^{\circ} \mathrm{C}$ corresponding to melting point of carrier Plasdone S630. The broad peak may be due to loss of water in polymer.

\section{Powder XRD analysis}

The powder XRD pattern of PAL and PALNP4 as shown Figs. 6 and 7 showed sharp high-intensity peaks indicating the presence of crystalline form.

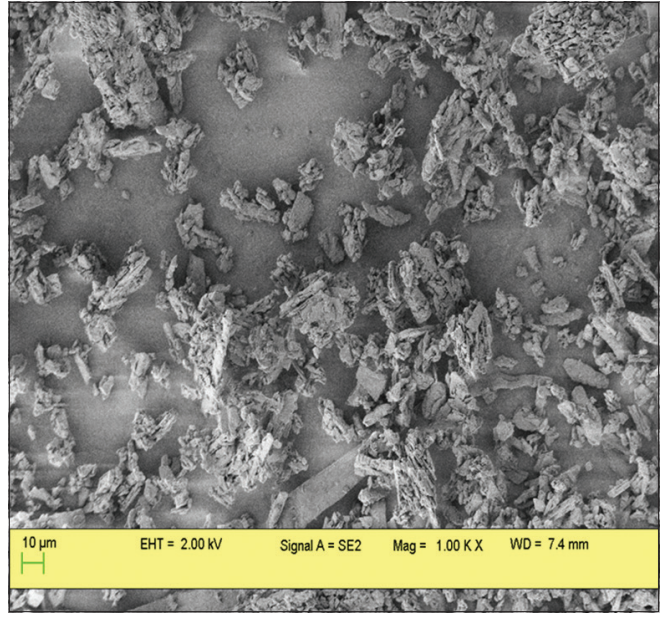

Fig. 8: Scanning electron microscopy of paliperidone

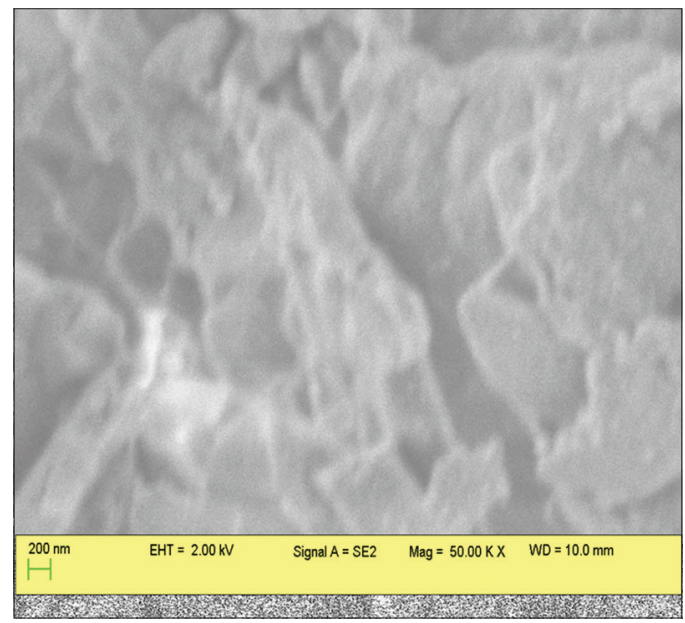

Fig. 9: Scanning electron microscopy of paliperidone nanoparticle 4

SEM

From the scanning electron microgram images as shown in Figs. 8 and 9, it can be seen that the pure drug particles existed as predominantly needle-shaped crystals; however, PAL NPs obtained by antisolvent precipitation are spherical or irregular in shape with a narrow PNP in the presence of Plasdone S630. Moreover, the nano-sized particles 


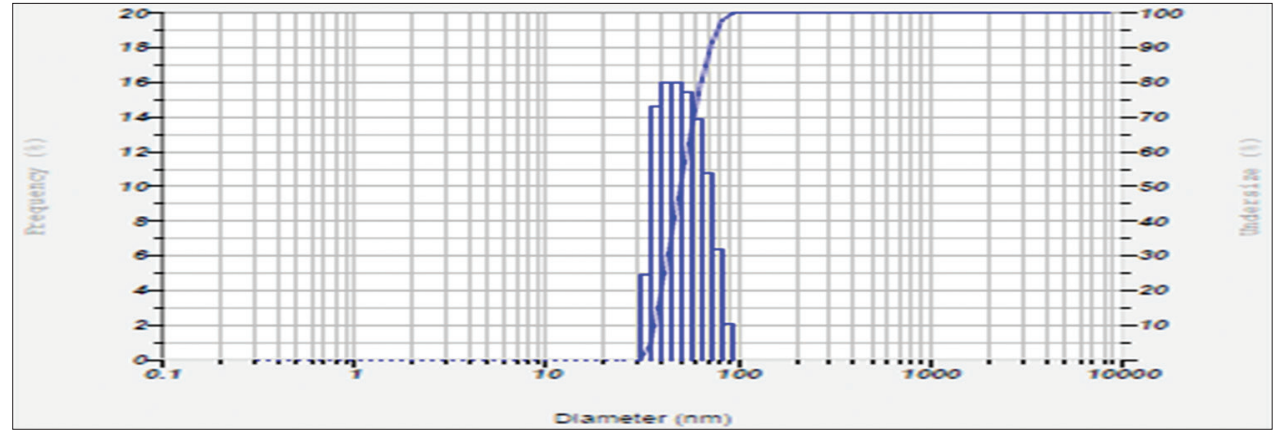

Fig. 10: Particle size of paliperidone nanoparticle 4

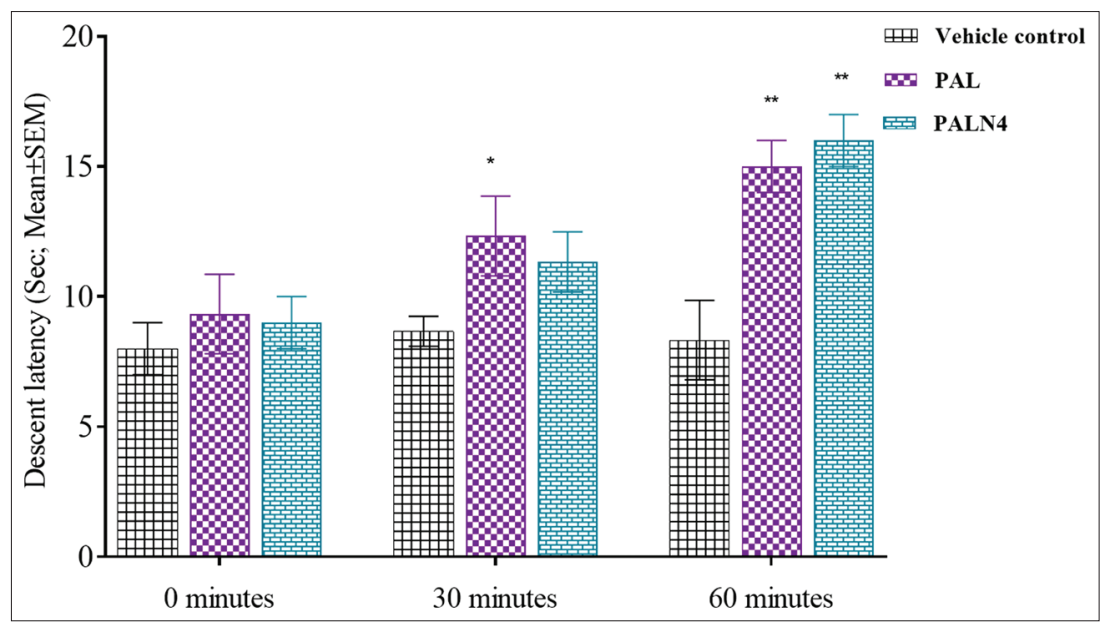

Fig. 11: Comparative effects of vehicle, paliperidone (PAL), and PAL nanoparticle 4 in bar test in mice. Results are expressed as mean \pm scanning electron microscopy, $(\mathrm{n}=6)$, Data were analyzed by one-way ANOVA followed by Dunnett's test, ${ }^{*} \mathrm{p}<0.05,{ }^{* *} \mathrm{p}<0.001$, NS: Non-significant when compared to vehicle-treated group

Table 3: Dissolution parameters of PAL, PALNPs, and PMs

\begin{tabular}{|c|c|c|c|c|c|}
\hline Formulation code & Ratio & DE60 & Q15 min & IDR in $15 \mathrm{~min}$ & $\mathrm{t} 75 \%(\mathrm{~min})$ \\
\hline PAL & $1: 0$ & $20.23 \pm 0.98$ & $16.42 \pm 1.09$ & $1.09 \pm 0.50$ & $>120$ \\
\hline NP1 & $1: 1$ & $21.35 \pm 0.85$ & $21.42 \pm 0.39$ & $1.42 \pm 0.56$ & $>120$ \\
\hline NP2 & $1: 3$ & $38.73 \pm 0.77$ & $41.42 \pm 0.71$ & $6.90 \pm 0.66$ & $>120$ \\
\hline NP3 & $1: 5$ & $57.35 \pm 1.03$ & $61.42 \pm 0.71$ & $4.09 \pm 1.33$ & $105 \pm 1.52$ \\
\hline NP4 & $1: 7$ & $69.35 \pm 1.27$ & $73.57 \pm 1.42$ & $4.90 \pm 1.57$ & $25 \pm 0.57$ \\
\hline PM1 (PAL:Plasdone S630) & $1: 7$ & $30.73 \pm 0.68$ & $31.42 \pm 0.71$ & $2.09 \pm 0.62$ & $>120$ \\
\hline NP5 & $1: 1$ & $19.35 \pm 0.90$ & $17.85 \pm 0.71$ & $1.29 \pm 0.57$ & $>120$ \\
\hline NP7 & $1: 5$ & $44.23 \pm 1.84$ & $46.42 \pm 1.09$ & $3.19 \pm 0.94$ & $>120$ \\
\hline NP8 & $1: 7$ & $52.1 \pm 2.32$ & $53.57 \pm 2.14$ & $3.57 \pm 0.77$ & $90 \pm 1.42$ \\
\hline PM2 (PAL:Povidone K25) & $1: 7$ & $23.23 \pm 1.05$ & $22.22 \pm 0.55$ & $1.48 \pm 0.77$ & $>120$ \\
\hline NP9 & $1: 1$ & $17.45 \pm 0.70$ & $18.75 \pm 0.71$ & $1.19 \pm 0.57$ & $>120$ \\
\hline NP10 & $1: 3$ & $31.99 \pm 0.73$ & $32.14 \pm 0.40$ & $2.14 \pm 0.48$ & $>120$ \\
\hline NP11 & 1:5 & $43.13 \pm 1.44$ & $45.42 \pm 0.89$ & $3.09 \pm 0.84$ & $>120$ \\
\hline NP12 & $1: 7$ & $50.11 \pm 2.02$ & $51.17 \pm 2.04$ & $3.47 \pm 0.47$ & $90 \pm 1.51$ \\
\hline PM3 (PAL:Povidone K30) & $1: 7$ & $22.25 \pm 1.04$ & $21.22 \pm 0.56$ & $1.46 \pm 0.75$ & $>120$ \\
\hline
\end{tabular}

PAL: Paliperidone, NP: Nanoparticle, PM: Physical mixture, DE60: Dissolution efficiency at 60, IDR: Initial dissolution rate

were very thin revealed by the presence of fragments. The images also revealed that these agglomerates or particle assemblies were composed of a large number of individual NPs.

\section{Particle size measurement}

The dynamic light scattering measurements as depicted in Fig. 10 show that all the particles falls below $100 \mathrm{~nm}$ with mean particle size $52.2 \mathrm{~nm}$ and with uniform particle size distribution.
In vivo antipsychotic activity evaluation of PAL and PALNP4 on bar test

Dopamine D2-like receptor antagonist shows increased descent latencies (tendency of animals to remain on bar). In the present study, mice treated with PAL or PALNP4 here exhibited significant change $(\mathrm{p}<0.001)$ in descent latency as compared to that of vehicletreated groups at respective time intervals indicating that PAL and PALNP4 elicited significant induction of cataleptic behavior (Table 4 
Table 4: Effects of vehicle, PAL, and PALNP4 in bar test in mice

\begin{tabular}{llll}
\hline $\begin{array}{l}\text { Treatment and dose } \\
\text { (mg/kg, p.o.) }\end{array}$ & $\begin{array}{l}\text { Descent latency (s) at various time } \\
\text { interval }\end{array}$ \\
\cline { 2 - 4 } & $\mathbf{0 ~} \mathbf{~} \mathbf{m}$ & $\mathbf{3 0} \mathbf{~} \mathbf{m i n}$ & $\mathbf{6 0} \mathbf{~ m i n}$ \\
\hline Vehicle $(10 \mathrm{ml} / \mathrm{kg})$ & $9.12 \pm 1.1$ & $8.24 \pm 0.87$ & $9.68 \pm 1.5$ \\
PAL & $8.9 \pm 1.0$ & $15.3 \pm 2.1^{*}$ & $15.7 \pm 2.1^{* *}$ \\
PALNP4 & $9.20 \pm 1.4$ & $11.2 \pm 2.3$ & $16.25 \pm 1.8^{* *}$ \\
\hline
\end{tabular}

Results are expressed as mean \pm SEM, $(n=6)$, Data were analyzed by one-way ANOVA followed by Dunnett's test, ${ }^{*} \mathrm{p}<0.05$, ${ }^{* *} \mathrm{p}<0.001$, NS: Non-significant when compared to vehicle-treated group, SEM: Scanning electron microscopy, PAL: Paliperidone, NP4: Nanoparticle 4

and Fig. 11). The induction of cataleptic behavior is the indication of the effect of antipsychotic agent(s).

\section{CONCLUSION}

PAL was successfully formulated in nanocrystals with desired characteristics of size and shape, with reasonable stability and entrapment with significantly greater solubility with faster dissolution rate compared to pure drug. Antisolvent precipitation can thus be a simple and effective approach to produce nanocrystals of poorly water-soluble drugs with hydrophilic carriers. In vitro release rate studies showed that the maximum drug release was found in the optimized PAL NPs 4. This may be due to increased surface area due to decreased particle size and improved wettability. Furthermore, from in vivo study, it seems that PALNP elicited significant antipsychotic-like activity as compared to PAL and vehicle control.

\section{ACKNOWLEDGMENT}

Authors are thankful to the School of Pharmacy, S.R.T.M. University, Nanded, for providing research facilities.

\section{AUTHOR'S CONTRIBUTIONS}

Both authors contributed throughout the work.

\section{CONFLICTS OF INTEREST}

There is no conflict of interest.

\section{REFERENCES}

1. Radtke M. Raw drug nanoparticles for the formulation of poorly soluble drugs. New Drugs 2001;3:62-8.

2. Lipinski C. Poor aqueous solubility: An industry wide problem in drug discovery. Am Pharm Rev 2002;5:82-5.

3. Patravale VB, Date AA, Kulkarni RM. Nanosuspensions: A promising drug delivery strategy. J Pharm Pharmacol 2004;56:827-40.

4. Rabinow BE. Nanosuspensions in drug delivery. Nat Rev Drug Discov 2004;3:785-96.

5. Wong SM, Kellaway IW, Murdan S. Enhancement of the dissolution rate and oral absorption of a poorly water soluble drug by formation of surfactant-containing microparticles. Int J Pharm 2006;317:61-8.

6. Dressman JB, Reppas C. In vitro-in vivo correlations for lipophilic, poorly water-soluble drugs. Eur J Pharm Sci 2000;11 Suppl 2:S73-80.
7. Kesisoglou F, Panmai S, Wu Y. Nanosizing-oral formulation development and biopharmaceutical evaluation. Adv Drug Deliv Rev 2007;59:631-44.

8. Bagul R, Mahajan V, Dhake A. New approaches in nanoparticulate drug delivery system-a review. Int J Curr Pharm Res 2012;4:29-38.

9. Banjare J. Application of nanotechnology in food technology and targeted drug therapy for prevention of obesity: An overview. J Crit Rev 2017;4:7-11.

10. Ruby JJ, Pandey VP. Chitosan nanoparticles as a nasal drug delivery for memantine hydrochloride. Int J Pharm Pharm Sci 2015;7:34-7.

11. Guo Z, Zhang M, Li H, Wang E, Kougouslos E. Effect of ultrasound on antisolvent crystallization process. J Cryst Growth 2005;273:555-63.

12. Louhi-Kultanen M, Karjalainen M, Rananen J, Huhtanen M, Kallas J. Crystallization of glycine with ultrasound. Int J Pharm 2006;320:23-9.

13. Dhumal RS, Biradar SV, Yamamura S, Paradkar AR, York P. Preparation of amorphous cefuroxime axetil nanoparticles by sonoprecipitation for enhancement of bioavailability. Eur J Pharm Biopharm 2008;70:109-15.

14. Verma S, Gokhale R, Burgess DJ. A comparative study of top-down and bottom-up approaches for the preparation of micro/nanosuspensions. Int J Pharm 2009;380:216-22.

15. Devalapally H, Chakilam A, Amiji MM. Role of nanotechnology in pharmaceutical product development. J Pharm Sci 2007;96:2547-65.

16. Galindo-Rodriguez S, Allémann E, Fessi H, Doelker E. Physicochemical parameters associated with nanoparticle formation in the salting-out, emulsification-diffusion, and nanoprecipitation methods. Pharm Res 2004;21:1428-39.

17. Hancock BC, Zografi G. Characteristics and significance of the amorphous state in pharmaceutical systems. J Pharm Sci 1997:86:1-2.

18. Matteucci ME, Hotze MA, Johnston KP, Williams RO $3^{\text {rd }}$. Drug nanoparticles by antisolvent precipitation: Mixing energy versus surfactant stabilization. Langmuir 2006;22:8951-9.

19. Park SJ, Jeon SY, Yeo SD. Recrystallization of a pharmaceutical compound using liquid and supercritical antisolvents. INP Eng Chem Res 2006;45:2287-93.

20. Pattekari P, Zheng Z, Zhang X, Levchenko T, Torchilin V, Lvov Y, et al. Top-down and bottom-up approaches in production of aqueous nanocolloids of low solubility drug paclitaxel. Phys Chem Chem Phys 2011;13:9014-9.

21. Noyes AA, Whitney WR, The rate of solution of solid substances in their own solutions. J Am Chem Soc 1897;19:930-4.

22. Gattani S, Moon R. Formulation and in vitro evaluation of tablet containing gliclazide nanocrystals for solubility and dissolution enhancement using soluplus. Int J Pharm Sci Res 2018;9:133-9.22.

23. Abdulbaqi MR. Evaluation the effect of nanotechnology on pharmaceutical and biological properties of metronidazole. Int J Pharm Pharm Sci 2017;9:139-45.

24. Khisti RT, Deshpande LS, Chopde CT. The neurosteroid 3 alpha-hydroxy-5 alpha-pregnan-20-one affects dopamine-mediated behavior in rodents. Psychopharmacology (Berl) 2002;161:120-8.

25. Ghorab M, Gardouh A, Gad S. Effect of viscosity, surfactant type and concentration on physicochemical properties of solid lipid nanoparticles. Int J Pharm Pharm Sci 2015;7:145-53.

26. Zhang HX, Wang JX, Zhang ZB, Le Y, Shen ZG, Chen JF, et al. Micronization of atorvastatin calcium by antisolvent precipitation process. Int J Pharm 2009;374:106-13.

27. Rogers TL, Gillespie IB, Hitt JE, Fransen KL, Crowl CA, Tucker CJ, et al. Development and characterization of a scalable controlled precipitation process to enhance the dissolution of poorly water-soluble drugs. Pharm Res 2004;21:2048-57.

28. Dawood NM, Hammid SN, Hussien AA. Formulation and characterization of lafutidine nanosuspension for oral drug delivery system. Int J App Pharm 2018;10:20-30. 